\title{
Expenditures on Mental Health Care in the Czech Republic in 2015
}

\section{Hana M. Broulikova ${ }^{1,2,3}$ (D) Martin Dlouhy $^{2}$ (D) Petr Winkler $^{1}$ (D)}

Published online: 26 November 2019

(C) The Author(s) 2019

\begin{abstract}
Expenditures on mental health care in the Czech Republic are not being published regularly, yet they are indispensable for evaluation of the ongoing reform of Czech mental health care. The main objective of this study is to estimate the size of these expenditures in 2015 and make a comparison with the last available figures from the year 2006. The estimation is based on an OECD methodology of health accounts, which structures health care expenditures according to health care functions, provider industries, and payers. The expenditures are further decomposed according to diagnoses, and inputs used in service production. The amount spent on mental health care in 2015 reached more than 13.7 billion Czech korunas (EUR 501.6 million), which represented 4.08\% of the total health care expenditures. This ratio is almost identical with the 2006 share $(4.14 \%)$. There are no significant changes in the relative expenditures on mental health care and in the structure of service provision. The Czech mental health care system remains largely hospital based with most of all mental health care expenditures being spent on inpatient care. Future developments in the expenditures will indicate the success of the current effort to deinstitutionalise mental health care.
\end{abstract}

Keywords Expenditures on psychiatric care $\cdot$ Central and Eastern Europe $\cdot$ Mental health care reform $\cdot$ Deinstitutionalization $\cdot$ OECD system of health accounts

Electronic supplementary material The online version of this article (https://doi.org/10.1007/s11126-01909688-3) contains supplementary material, which is available to authorized users.

Hana M. Broulikova

h.m.broulikova@vu.nl

1 Department of Public Mental Health, National Institute of Mental Health, Topolová 748, 25067 Klecany, Prague, Czech Republic

2 Faculty of Informatics and Statistics, University of Economics, Prague, Czech Republic

3 Department of Health Sciences, Faculty of Science, Vrije Universiteit Amsterdam, De Boelelaan 1105, 1081 HV Amsterdam, the Netherlands 


\section{Introduction}

The societal burden of mental health problems has so far not been met with an adequate response [1]. More than a quarter of people experience a mental health problem every year [2-5]. The societal costs of mental disorders reached 461 billion euro in Europe in 2010 [6]. Depression is now a leading cause of disability worldwide [7], and in Europe mental health problems account for $8.9 \%$ of all DALYs [8]. Yet, the average expenditures on mental disorders do not match their burden, especially in the case of Eastern Europe: While the mental health care expenditures amounted on average to $7 \%$ of the total health care budget of the old fifteen EU countries, in Eastern European countries this share reached only $3.3 \%$ according to the WHO 2011 Mental Health Atlas.[9]. The last available estimate for the Czech Republic (2006) is 4.14\% [10].

The Czech Republic is a post-communist EU country with 10.5 million inhabitants. More than $80 \%$ of total health care financing is covered by public financing [11]. This comprises of mandatory public health insurance and of public budgets with the former being the most important source of health financing in the country. Public health insurance is administered by health insurance funds, which are public organizations collecting insurance premiums and purchasing services from health providers. All Czech public health insurance funds can operate nationally and compete for members.

Mental health care is an integral part of the Czech national health system. The system annually serves more than 600 thousand people with mental health disorders [12]. Majority of patients receive outpatient care delivered by psychiatrists in private practices. There is no gatekeeping, so a patient can visit a psychiatrist without a referral from a general practitioner. Inpatient care is provided in psychiatric departments of general hospitals and in specialized psychiatric hospitals.

The mental health care reform that was launched in 2013 ought to bring about considerable changes in the services and in the expenditures [13]. The goals of the reform include improving the quality of life of people with mental illness, reducing stigmatisation, increasing the satisfaction of patients and the efficacy of psychiatric care, improving the linkage between health and social services, and humanising psychiatric care [14]. In addition, as the Czech mental health care system is still largely hospital based, one of the major aims of the reform is to shift the locus of care from large psychiatric hospitals to communities [14-17]. To enable this deinstitutionalisation, the reform introduces new mental health centres (MHCs), which should be developed for catchment areas of 100,000 inhabitants and offer community services for people with severe mental illnesses. An MHC multidisciplinary team is staffed by psychiatric nurses, social workers, psychiatrists and psychologists. It provides mobile case management services, crisis interventions, day care services, and out-patient psychiatric and psychological care [18]. In 2018, the first MHCs started their pilot operation, which is - similarly to other transformation activities - financed from EU funds. After the first 18 months of operation of these MHCs, public health insurance and regional social budgets are supposed to secure their sustainable financing. Consequently, the OECD accounts will allow us to assess whether the effort to deinstitutionalise patients is reflected in the change of the structure of financed services. The shifts in expenditures from inpatient to outpatient care constitute an important indicator of the reform's success which is why it is important to closely monitor this indicator now as well as in the future.

The aim of this article is to provide up to date estimates of the mental health expenditures in the Czech Republic and to analyse their development. Consistently with the last estimates from 2006, we aimed to use the OECD methodology of health accounts that has been developed to provide a 
consistent guidance on health expenditures calculation $[19,20]$. This methodology provides a standardised framework allowing to sort expenditures according to different perspectives and to answer the questions who pays for mental health services, who the providers are and what services they deliver. Consequently, the resulting figures are suitable for international comparison. Although the Czech Statistical Office annually publishes health accounts based on the OECD methodology, the reported expenditures cannot be disaggregated according to diagnostic groups and, thus, information about mental health expenditures cannot be retrieved. Our study combines multiple data sources to fill this gap. In addition to the standard OECD perspectives, we estimate expenditures according to diagnoses and according to inputs used in service production.

\section{Methods}

We adhered to the OECD methodology on health accounts SHA 1.0 [20] and its revisions SHA 2011 [19]. This methodology constructs the accounts from three different perspectives: health care functions (ICHA-HC, Table 1), provider industries (ICHA-HP, Table 2), and payers (ICHA-HF, Table 3). Each of the perspectives divides health care expenditures into individual chapters according to a different criterion. The health care function account attributes expenditures for example to services of curative care, and rehabilitative care. The provider industry perspective sorts expenditures according to the type of facility within which they were incurred, including hospitals, or providers of ambulatory care. The health care function account as well as the provider industry account include also chapters on medical goods provision, prevention, and health care administration. The perspective of payers categorizes expenditures according to who incurred them into the chapters of government and compulsory health insurance financing schemes, voluntary financing schemes, and household out-of-pocket payment.

Several remarks are needed as far as the construction of our accounts is concerned. The methodology sometimes asks for a higher degree of disaggregation than we were able to achieve; when this is the case, the table shows not disaggregated (ND) for the respective subchapter. We also had to address the changes brought by the revised version of the methodology SHA 2011. First, the SHA 2011 renames some chapters and subchapters, and slightly changes the structure of the accounts. We reassigned the 2006 expenditures to facilitate comparisons. Second, paying greater attention to social services provided to patients, SHA 2011 introduces a new chapter long-term social care (HCR.1). This expands the calculated size of the total health care budget. To allow comparability with the 2006 figure, we report both the 2015 share of mental health expenditures in the total health expenditure including the new chapter (SHA 2011) as well as the share in the total expenditure that excludes it (SHA 1.0).

In addition to the OECD methodology, we further classify expenditures according to groups of related diagnoses (Table 4). These groups are based on the internationally recognized 10th revision of the International Statistical Classification of Diseases and Related Health Problems (ICD-10) [21]. Lastly, we also consider the perspective of inputs entering production of health care services (Table 5). The complete methodological procedure and results are available in Online Resource 1.

\section{Data}

The main data sources are public reports collected from the General Health Insurance Fund (GHIF), the Czech Statistical Office (CSO), and The Institute of Health Information and 
Statistics of the Czech Republic (IHIS). These resources were complemented by unpublished information from the Ministry of Health of the Czech Republic and GHIF. GHIF is the largest health insurer in the Czech Republic. Two thirds of the population are enrolled with this insurer, which provides a certain guarantee of representativeness [22]. The insurerannually publishes a comprehensive yearbook [23] with a detailed description of enrolees, collected premiums, services provided by contracted health facilities, and related expenditures. This document specifies total expenditures, expenditures on psychopharmaceuticals, and expenditures on rehabilitative spas. The GHIF further provided unpublished financial data on ambulatory psychiatric care, psychiatric hospitals, and psychiatric departments in general hospitals as well as the relative resource consumption by each diagnostic group. The CSO annually publishes accounts based on the OECD methodology for the entire national system of health care [11]. For our analysis, we use the information about total health care expenditures and expenditures on health administration contained in these accounts. In 2013, IHIS reported the structure of costs for selected types of health care establishments that serves as a basis for our input category perspective [24]. The results are converted from Czech korunas (CZK) to euro (EUR) with the annual average of the daily nominal exchange rate in 2015: EUR $1=$ CZK 27.283 [25].

Mental health expenditures are defined as health expenditures on services for patients with primary or first-listed diagnoses from Chapter V, Mental and Behavioural Disorders (F00-F99), of the Tenth Revision of International Classification of Diseases (ICD-10). By this definition we exclude expenditures on somatic illnesses that can be partially a consequence of mental health conditions (for example cirrhosis of liver as a consequence of alcohol addiction). The study further excludes disability pensions, sickness benefits, and also services for the mentally ill that are considered as social services in the Czech context. Such types of expenditures are financed from social care budgets, mainly by central and local governments. Unfortunately, there is no reliable data source that would allow us to identify the share of the social care budget allocated to mental health issues. Due to a lack of reliable data, the study also excludes services for the mentally ill provided by general practitioners.

\section{Health Care Function Perspective (ICHA-HC)}

The health care function perspective allocates expenditures to the following chapters and subchapters that are applicable in the context of the Czech Republic: curative care (chapter HC.1, subchapters HC.1.1 inpatient curative care in psychiatric and general hospitals and HC.1.3 outpatient curative care), rehabilitative care (HC.2, subchapter HC.2.1 inpatient rehabilitative care), ancillary services (HC.4, subchapter HC.4.3 patient transportation), medical goods (HC.5, subchapter HC.5.1 pharmaceuticals and other medical non-durable goods), and governance and health system financing and administration (HC.7, data not disaggregated into subchapters). Rehabilitative care refers in the Czech context to health spa. Patient transportation includes emergency cases only. Medical goods denote outpatient pharmaceuticals while inpatient pharmaceuticals are a part of inpatient expenditures.

First, we calculated the shares of particular functions on the total yearly expenditures of GHIF (from both published [23] and unpublished sources). The sum of these shares gives a relative proportion of mental health care expenditures to total health care expenditures. Second, assuming that for other insurers and sources of financing the shares are equivalent, we subsequently applied them to the total national health care expenditures reported by the 
$\mathrm{CSO}$ [11] to get mental health expenditures for the whole system. Expenditures on preventive care (chapter HC.6 of ICHA-HC), long-term social care (chapter HCR.1), health promotion (chapter HCR.2), investments, education, and research and development (chapters R.1, R.2, R.3) were excluded from the amount of total health care expenditures. The reason is that most of these chapters are complementary to health care expenditures rather than constituting their organic part. Moreover, we expect a large heterogeneity in spending across particular health care fields within these chapters. Consequently, applying the assumption that expenditures on these chapters correspond to the fraction of the total budget of GHIF consumed by mental health care would mislead the results. On the other hand, we consider reasonable to apply this assumption to mental-health care administration (chapter HC.7) as there is no compelling reason why mental-health care administration should be differently demanding than administration in other health care fields.

\section{Provider Industry Perspective (ICHA-HP)}

To categorize expenditures according to provider industries, figures on health care functions were clustered together according to institutional settings in which care is provided. The most relevant chapters are hospitals (HP.1) and providers of ambulatory health care (HP.3). Hospitals are further subdivided into general hospitals (HP.1.1), psychiatric hospitals (HP.1.2), and health spas (coded as specialized hospitals HP.1.3). The ambulatory care provided in hospitals is allocated to subchapter HP.1.1 and ambulatory care provided by independent medical practices is allocated to subchapter HP.3.1. The chapters representing providers of medical goods (HP.5) and health administration (HP.7) display the same figures as the corresponding chapters under the health care function perspective.

\section{Payer Perspective (ICHA-HF)}

To offer the payer perspective, we start from the CSO classification of national health expenditures by the type of the financing entity. The applicable chapters are government schemes and compulsory contributory health care financing schemes (HF.1, subchapters HF.1.1.1/2 government schemes further divided to the central and local government schemes, and HF.1.2 compulsory contributory health insurance schemes), voluntary health care payment schemes (HF.2, subchapters voluntary health insurance schemes HF.2.1, non-profit financing schemes HF.2.2, and enterprise financing schemes HP2.3), and household out-of-pocket payment (HF.3).

We assume that the shares of different budgeting segments are the same for the mental health care accounts as for the general health care accounts. We calculate the share of each budgeting segment and apply it to the national expenditures on mental health care.

\section{Diagnosis Perspective}

An unpublished data from GHIF shows how its reimbursements to providers of mental health care are divided among different diagnostic groups. We consider separately outpatient medical practices (HP.3.1), psychiatric departments of general hospitals (HP.1.1), psychiatric hospitals (HP.1.2) and providers of medical goods (HP.5). To extrapolate the information to the whole system, we multiply the estimates of expenditures on a given provider industry from the table ICHA-HP with the share that each diagnostic group consumes according to GHIF. 


\section{Input Costs Perspective}

To divide expenditures according to input categories such as labour or material, we use shares of inputs published by IHIS in 2013, which cover psychiatric as well as general hospitals. We assume that shares of input costs at psychiatric departments of general hospitals correspond to the shares of input costs at general hospitals as a whole. Expenditures on inputs for psychiatric hospitals and departments are then calculated by division of expenditures per a type of provider in 2015 according to the shares published by IHIS.

\section{Results}

National mental health care expenditures reached 13.7 billion CZK (EUR 501.6 million), which is 1297 CZK (EUR 48) per capita in the Czech Republic in 2015. Relatively, mental health care expenditures represent $4.08 \%$ of the total health care budget according to the original guidelines SHA 1.0 [20]. The inclusion of a chapter on long run social care (HCR.1) recognized by the revised version SHA 2011 [19] into the total budget further decreases the estimate of mental health share to $3.87 \%$.

Three quarters of the mental health care budget is spent on services of curative care. These expenditures are mainly driven by inpatient care, costing 8.4 billion (EUR 306.5 million, $61.1 \%$ of the entire budget). To compare, outpatient care cost 1.9 billion (EUR 70 million, 14\%). Hospitals consumed 8.6 billion (EUR 315.5 million, 62.9\%). Specifically, 7.6 billion (EUR 279.4 million, 55.7\%) was spent on psychiatric hospitals, with the rest of the chapter being allocated to psychiatric departments of general hospitals and mental health spas. The largest part (30\%) of the budget was allocated to schizophrenia, schizotypal and delusional disorders (F20-F29). The share of public financing reached $84.6 \%$ in 2015 [11]. Public budgets and public health insurance spent 11.6 billion (EUR 424.5 million) on mental health care. Of this amount, 9.1 billion (EUR 332.8 million) was paid by public health insurers. The most expensive input used in the production of mental health care was labour (65\%, CZK 5.6 billion, EUR 203.5 million). Tables 1, 2, 3,4 and 5 report complete results categorized from the perspective of health care functions (Table 1), provider industries (Table 2), source of financing (Table 3), diagnostic groups (Table 4) and input cost categories (Table 5).

\section{Discussion}

While the period between 2001 and 2006 marked an increase in the share of mental health care on the total health care expenditures from 3.54\% [10] to $4.14 \%$ [26], our results suggest that this share remained roughly constant during the last decade, reaching $4.08 \%$ in 2015. This means that the Czech share of mental health expenditures amounts only to two thirds of the median value $6.3 \%$ observed in the European WHO region [9, 27], and two fifths of what is recommended [1]. Such a low proportion of health budget spent on mental health is clearly a sign of structural discrimination and a failure to allocate resources that would correspond to the overall societal burden caused by mental disorders [1].

The structure of expenditures has changed only slightly between 2006 and 2015 . The share of expenditures on curative care (HC.1) increased from $71.7 \%$ to $75.1 \%$ mainly due to a 
Table 1 Mental health expenditures by the OECD ICHA-HC classification of health-care services/functions, Czech Republic, 2015

\begin{tabular}{lll}
\hline Health care function & $\begin{array}{l}\text { Mental health expenditures 2015, } \\
\text { millions CZK (EUR) }\end{array}$ & $\begin{array}{l}\text { Share of function, } \\
2015(2006)\end{array}$ \\
\hline HC.1 Curative care & $10,272(376.5)$ & $75.1 \%(71.7 \%)$ \\
HC.1.1 Inpatient curative care & $8361(306.5)$ & $61.1 \%(56.3 \%)$ \\
HC.1.2 Day curative care & 0 & $0 \%(0 \%)$ \\
HC.1.3 Outpatient curative care & $1910(70)$ & $14 \%(15.3 \%)$ \\
HC.1.4 Home-based curative care & 0 & $0 \%(0 \%)$ \\
HC.2 Rehabilitative care & $59(2.2)$ & $0.4 \%(0.4 \%)$ \\
HC.2.1 Inpatient rehabilitative care & $59(2.2)$ & $0.4 \%(0.4 \%)$ \\
HC.2.2 Day rehabilitative care & 0 & $0 \%(0 \%)$ \\
HC.2.3 Outpatient rehabilitative care & 0 & $0 \%(0 \%)$ \\
HC.2.4 Home-based rehabilitative care & 0 & $0 \%(0 \%)$ \\
HC.3 Long-term care (health) & 0 & $0 \%(0 \%)$ \\
HC.4 Ancillary services (non-specified & $286(10.5)$ & $2.1 \%(0 \%)$ \\
$\quad$ by function) & ND & \\
HC.4.1 Laboratory services & ND & $2.1 \%(0 \%)$ \\
HC.4.2 Imaging services & $286(10.5)$ & $19.8 \%(25.9 \%)$ \\
HC.4.3 Patient transportation & $2713(99.4)$ & $19.8 \%(25.9 \%)$ \\
HC.5 Medical goods (non-specified & by function) & \\
HC.5.1 Pharmaceuticals and other medical & $2713(99.4)$ & $0 \%(0 \%)$ \\
$\quad$ non-durable goods & & $0 \%(0 \%)$ \\
HC.5.2 Therapeutic appliances and other & 0 & $2.6 \%(2.1 \%)$ \\
$\quad$ medical goods & &
\end{tabular}

growth in resources allocated to inpatient curative care (HC.1.1, from $56.3 \%$ to $61.1 \%$ ) in psychiatric hospitals (HP.1.2 from 52.4 to $55.7 \%$ ). This development is mirrored in a relative decrease of expenditures on outpatient pharmaceuticals (HC.5.1), which dropped from $25.9 \%$ to $19.8 \%$ of the total expenditures on mental health care.

We further observed a slight decrease in the share of expenditures paid from public budgets (HF.1) from $88 \%$ in 2006 to $84.6 \%$ in 2015 . Within this chapter, the contribution of compulsory health insurance schemes (HF.1.2) dropped from $77.7 \%$ to $66.4 \%$. In contrast, the share of central and local governments increased from $10.3 \%$ to $18.3 \%$. In addition, more resources were paid through voluntary health care payment schemes (HF.2, increase from $0.5 \%$ to $2.6 \%$ ). The main change within this chapter pertains to the jump from 0 to $2.2 \%$ in the case of non-profit organizations (HF.2.2). However, the question is whether this change reflects actual differences in financing or just a new statistical awareness of this type of expenditures. Interestingly, private out-of-pocket expenditures remain stable ( $11.5 \%$ vs. $12.7 \%)$.

Our estimates on resources consumed by different diagnostic groups correct the figures from 2006, which were based on a strong assumption that - within each industry - care is equally expensive for every patient regardless of his or her psychiatric diagnosis. Consequently, in 2006, the diagnostic group deemed as most costly consisted 
Table 2 Mental health expenditures by the OECD ICHA-HP classification of health providers, Czech Republic, 2015

\begin{tabular}{|c|c|c|}
\hline Health care provider & $\begin{array}{l}\text { Mental health expenditures } \\
\text { 2015, millions CZK (EUR) }\end{array}$ & $\begin{array}{l}\text { Share of provider, } \\
2015 \text { (2006) }\end{array}$ \\
\hline HP.1 Hospitals & $8608(315.5)$ & $62.9 \%(59 \%)$ \\
\hline HP.1.1 General hospitals & $926(33.9)$ & $6.8 \%(6.6 \%)$ \\
\hline HP.1.2 Mental health hospitals & $7623(279.4)$ & $55.7 \%(52.4 \%)$ \\
\hline $\begin{array}{l}\text { HP.1.3 Specialised hospitals (other than mental } \\
\text { health hospitals) }\end{array}$ & $59(2.2)$ & $0.4 \%(0: 4 \%)$ \\
\hline HP.2 Residential long-term care facilities & 0 & $0 \%(0 \%)$ \\
\hline HP.3 Providers of ambulatory health care & $1723(63.1)$ & $12.6 \%(12.6 \%)$ \\
\hline HP.3.1 Medical practices & $1723(63.1)$ & $12.6 \%(12.6 \%)$ \\
\hline HP.3.2 Dental practice & 0 & $0 \%(0 \%)$ \\
\hline HP.3.3 Other health care practitioners & ND & \\
\hline HP.3.4 Ambulatory health care centres & ND & \\
\hline HP.3.5 Providers of home health care services & ND & \\
\hline HP.4 Providers of ancillary services & $286(10.5)$ & $2.1 \%(0 \%)$ \\
\hline $\begin{array}{l}\text { HP.4.1 Providers of patient transportation and emergency } \\
\text { rescue }\end{array}$ & $286(10.5)$ & $2.1 \%(0 \%)$ \\
\hline HP.4.2 Medical and diagnostic laboratories & ND & \\
\hline HP.4.9 Other providers of ancillary services & ND & \\
\hline HP.5 Retailers and other providers of medical goods & $2713(99.4)$ & $19.8 \%(25.9 \%)$ \\
\hline HP.5.1 Pharmacies & ND & \\
\hline $\begin{array}{l}\text { HP.5.2 Retail sellers and other suppliers of durable } \\
\text { medical goods and medical appliances }\end{array}$ & ND & \\
\hline $\begin{array}{l}\text { HP.5.9 All other miscellaneous sellers and other suppliers } \\
\text { of pharmaceuticals and medical goods }\end{array}$ & ND & \\
\hline HP.6 Providers of preventive care & 0 & $0 \%(0 \%)$ \\
\hline $\begin{array}{l}\text { HP.7 Providers of health care system administration and } \\
\text { financing }\end{array}$ & $356(13)$ & $2.6 \%(2.1 \%)$ \\
\hline HP.7.1 Government health administration agencies & ND & \\
\hline HP.7.2 Social health insurance agencies & ND & \\
\hline HP.7.3 Private health insurance administration agencies & ND & \\
\hline HP.7.9 Other administration agencies & ND & \\
\hline HP.8 Rest of economy & 0 & $0 \%(0 \%)$ \\
\hline HP.9 Rest of the world & 0 & $0 \%(0 \%)$ \\
\hline Total & $13,685(501.6)$ & $100 \%$ \\
\hline
\end{tabular}

of neurotic, stress related and somatoform disorders (F40-F48; F50-F59) due to a large number of patients suffering from these disorders. Although the shares of patients remained similar (see Online Resource 1, sheet Patients), in 2015, the most expensive group of diagnoses included schizophrenia, schizotypal and delusional disorders (F20F29) consuming $30 \%$ of the budget. To illustrate this disproportionality in respect to a particular industry, whereas the said disorders accounted only for $19 \%$ of patients in psychiatric hospitals, they consumed 35\% of the hospitals' budget. Another recent study [28] moreover shows that the costs of community care for these disorders - and for other non-affective psychoses - are significantly lower than the costs of their inpatient care (about 350 thousand CZK per patient) while being similarly effective. Schizophrenia, schizotypal and delusional disorders thus appear to be apt candidates for deinstitutionalization of the care $[10,29]$. The success of the reform effort to achieve deinstitutionalization, concerning this as well as other diagnostic groups, will be indicated by future changes in the expenditures and mainly in their structure. 
Table 3 Mental health expenditures by the OECD ICHA-HF classification of health-care financing, Czech Republic, 2015

\begin{tabular}{lll}
\hline Health-care financing & $\begin{array}{l}\text { Mental health expenditures } \\
2015, \text { millions CZK (EUR) }\end{array}$ & $\begin{array}{l}\text { Share of financing } \\
\text { budget, 2015 (2006) }\end{array}$ \\
\hline $\begin{array}{l}\text { HF.1 Government schemes and compulsory } \\
\quad \text { contributory health care financing schemes }\end{array}$ & $11,582(424.5)$ & $84.6 \%(88 \%)$ \\
HF.1.1 Government schemes & $2501(91.7)$ & $18.3 \%(10.3 \%)$ \\
HF.1.1.1 Central government schemes & $2124(77.8)$ & $15.5 \%(6.5 \%)$ \\
HF.1.1.2 State/regional/local government schemes & $378(13.8)$ & $2.8 \%(3.8 \%)$ \\
HF.1.2 Compulsory contributory health & $9080(332.8)$ & $66.4 \%(77.7 \%)$ \\
$\quad$ insurance schemes & 0 & $0 \%(0 \%)$ \\
HF.1.3 Compulsory Medical Saving Accounts & & $2.6 \%(0.5 \%)$ \\
$\quad$ CMSA) & $361(13.2)$ & $0.1 \%(0 \%)$ \\
HF.2 Voluntary health care payment schemes & $18(0.7)$ & $2.2 \%(0 \%)$ \\
HF.2.1 Voluntary health insurance schemes & $307(11.2)$ & $0.3 \%(0.5 \%)$ \\
HF.2.2 NPISH financing schemes & $35(1.3)$ & $12.7 \%(11.5 \%)$ \\
HF.2.3 Enterprise financing schemes & $1743(63.9)$ & $100 \%$ \\
HF.3 Household out-of-pocket payment & $13,685(501.6)$ & \\
Total &
\end{tabular}

The strength of this study is that we use official data provided by reliable institutions to construct mental health care accounts according to an internationally recognized methodology. Moreover, the unavoidable assumptions used for calculations are consistent with the similar study conducted in 2006, which enables time comparison.

The results might nevertheless be influenced by reporting practices of the CSO. Its adoption of the new OECD methodology led to an immediate increase in some of the account chapters, especially in regard to long term care; the total and administrative expenditures, which we use in our calculations, might hence be distorted. Further, it is not clear to what extent the accounts reflect expenditures on some mental health services on the boundary of social and health care such as the community centres, which are paid for by the Ministry of Labour and Social Affairs instead of by public health insurers. Since we work with the composition of services financed by the GHIF as one of these insurers, our calculations fail to assign the community centre expenditures (to the extent to which the CSO actually does include them in the figures that it reports) to the category of outpatient care. Instead, our methodology divides these expenditures among all categories of services according to their shares calculated from the GHIF data. As a result, the category of outpatient care could be biased downwards. Nevertheless, we believe that the magnitude of error is modest because community services are still provided on a rather small scale in the Czech Republic [14]. Another distortion in the expenditures structure was caused by an unavailability of information on the emergency service expenditures (chapters HC.4.3 and HP.4.1 respectively) for the year 2006. As a result of these comparability issues, the subtle changes in the structure of expenditures that we observe should not be seen as conclusive manifestations of actual expenditure trends.

\section{Conclusion}

This study estimates expenditures on mental health care in the Czech Republic in 2015. The results suggest that the share of these expenditures on the total health care budget had remained constant over the previous ten years, staying well below the European average. Developments 


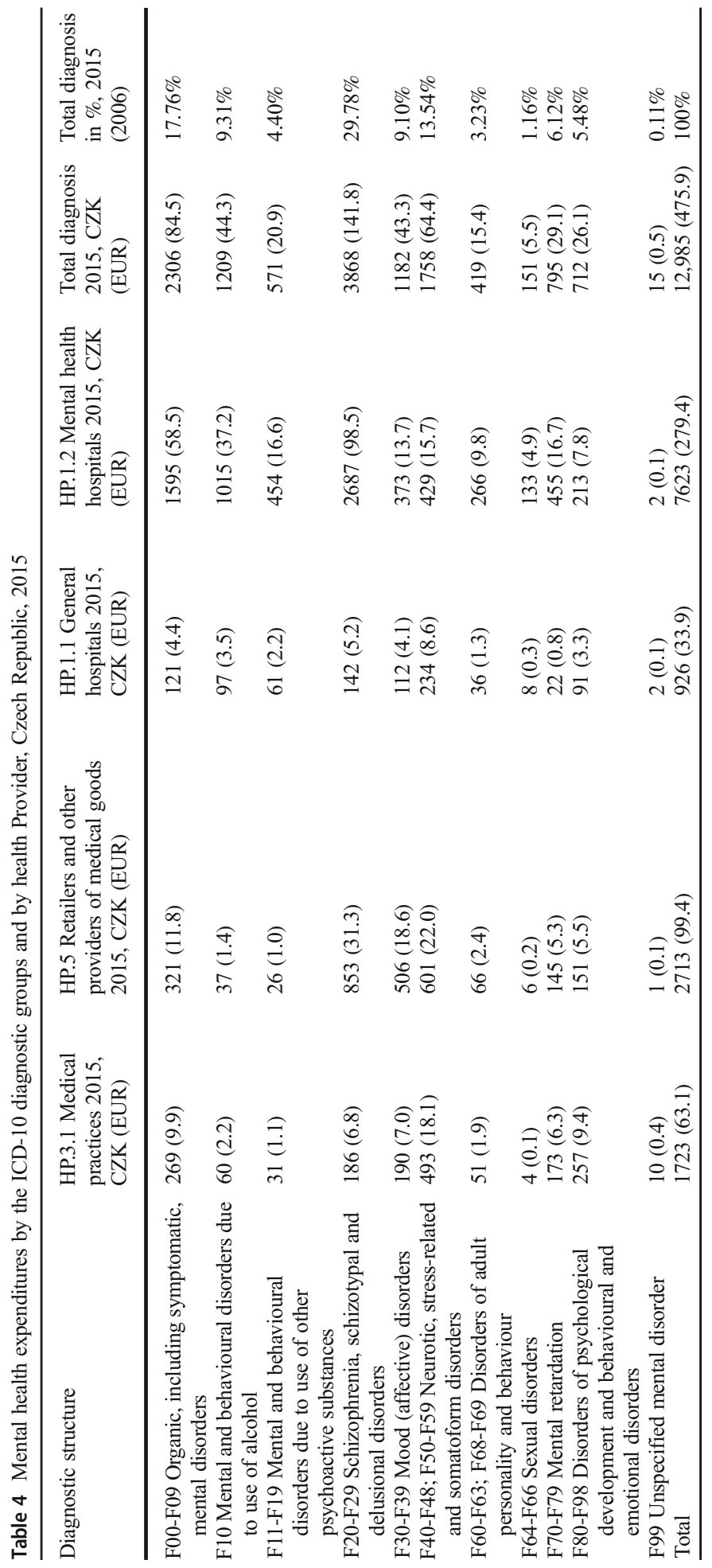


Table 5 Mental health expenditures by cost category, general and mental health hospitals only, Czech Republic, 2015

\begin{tabular}{|c|c|c|c|c|c|}
\hline Category & $\begin{array}{l}\text { General } \\
\text { hospital in \%, } \\
2015 \text { (2006) }\end{array}$ & $\begin{array}{l}\text { Psychiatric } \\
\text { hospital in \%, } \\
2015 \text { (2006) }\end{array}$ & $\begin{array}{l}\text { General hospital } \\
\text { expenditure } 2015 \text {, } \\
\text { millions CZK (EUR) }\end{array}$ & $\begin{array}{l}\text { Psychiatric hospital } \\
\text { expenditure } 2015 \text {, } \\
\text { millions CZK (EUR) }\end{array}$ & $\begin{array}{l}\text { Category total } \\
\text { 2015, millions } \\
\text { CZK (EUR) }\end{array}$ \\
\hline $\begin{array}{c}\text { Personal } \\
\text { Cost }\end{array}$ & $\begin{array}{l}46.3 \% \\
\quad(43.7 \%)\end{array}$ & $\begin{array}{l}67.2 \% \\
(63.7 \%)\end{array}$ & 429 (15.7) & $5123(187.8)$ & $5551(203.5)$ \\
\hline Drugs & $\begin{array}{l}13.7 \% \\
\quad(8.3 \%)\end{array}$ & $3.3 \%(4.1 \%)$ & $127(4.7)$ & $252(9.2)$ & 378 (13.9) \\
\hline $\begin{array}{l}\text { Special } \\
\text { medical } \\
\text { materials }\end{array}$ & $\begin{array}{l}12.8 \% \\
\quad(13.9 \%)\end{array}$ & $1.6 \%(1.9 \%)$ & $119(4.3)$ & $122(4.5)$ & $241(8.8)$ \\
\hline Blood & $1.1 \%(1.2 \%)$ & $0 \%(0 \%)$ & $10(0.4)$ & 0 & $10(0.4)$ \\
\hline Food & $0.8 \%(1.1 \%)$ & $4.7 \%(4.9 \%)$ & $7(0.3)$ & $358(13.1)$ & $366(13.4)$ \\
\hline Energy & $3.1 \%(3.1 \%)$ & $5.9 \%(6.3 \%)$ & $29(1.1)$ & $450(16.5)$ & $478(17.5)$ \\
\hline Services & $7.2 \%(8 \%)$ & $7.3 \%(7.7 \%)$ & $67(2.4)$ & $556(20.4)$ & $623(22.8)$ \\
\hline Depreciation & $4.6 \%(5.4 \%)$ & $3.3 \%(3.1 \%)$ & 43 (1.6) & $252(9.2)$ & $294(10.8)$ \\
\hline Other & $\begin{array}{l}10.4 \% \\
\quad(15.2 \%)\end{array}$ & $6.6 \%(8.3 \%)$ & $96(3.5)$ & 503 (18.4) & $599(22)$ \\
\hline Total & $100 \%$ & $100 \%$ & 926 (33.9) & $7623(279.4)$ & $8541(313.1)$ \\
\hline
\end{tabular}

in mental health expenditures will serve as an important indicator for evaluation of the current effort to deinstitutionalise mental health care. An important task for future research is to investigate the part of these expenditures that is incurred by social care budgets, mainly as regards community mental health care.

Funding Information The study was supported by the project "Sustainability for the National Institute of Mental Health" (grant LO1611), with a financial support from the Ministry of Education, Youth and Sports of the Czech Republic, and the project "MERRPS" (grant CZ.033.X/0.0/0.0/15_124/0006067), with a financial support from the Ministry of Social Affairs of the Czech Republic. Conflict of Interest: The authors declare that they have no conflict of interest. Ethical Approval: This article does not contain any studies with human participants or animals performed by any of the authors.

\section{Compliance with Ethical Standards}

Disclaimer This paper has not been published elsewhere, is not under consideration by another journal, and has not been presented at any conference or professional meeting.

Open Access This article is distributed under the terms of the Creative Commons Attribution 4.0 International License (http://creativecommons.org/licenses/by/4.0/), which permits unrestricted use, distribution, and reproduction in any medium, provided you give appropriate credit to the original author(s) and the source, provide a link to the Creative Commons license, and indicate if changes were made.

\section{References}

1. Patel V, Saxena S, Lund C, Thornicroft G, Baingana F, Bolton P, et al. The lancet commission on global mental health and sustainable development. Lancet. 2018;392(10157):1553-98.

2. Wittchen HU, Jacobi F, Rehm J, Gustavsson A, Svensson M, Jönsson B, et al. The size and burden of mental disorders and other disorders of the brain in Europe 2010. Eur Neuropsychopharmacol. 2011;21(9): 655-79.

3. Wittehen HU, Jacobi F. Size and burden of mental disorders in Europe- a critical review and appraisal of 27 studies. Eur Neuropsychopharmacol. 2005;15(4):357-76. 
4. World Health Organization. The European mental health action plan 2013-2020. Copenhagen: World Health Organization; 2013.

5. Formánek T, Kagström A, Cermakova P, Csémy L, Mladá K, Winkler P. Prevalence of mental disorders and associated disability: Results from the cross-sectional CZEch mental health Study (CZEMS). European Psychiatry. 2019;60:1-6.

6. Gustavsson A, Svensson M, Jacobi F, Allgulander C, Alonso J, Beghi E, et al. Cost of disorders of the brain in Europe 2010. Eur Neuropsychopharmacol. 2011;21(10):718-79.

7. World Health Organization. Depression and other common mental disorders: global health estimates. Geneva: World Health Organization; 2017.

8. Global Burden of Disease Collaborative Network. Global Burden of Disease Study 2016 (GBD 2016) Incidence, Prevalence, and Years Lived with Disability 1990-2016. Seattle, United States: Institute for Health Metrics and Evaluation (IHME); 2017.

9. Krupchanka D, Winkler P. State of mental healthcare systems in Eastern Europe: do we really understand what is going on? BJPsych Int. 2016;13(4):96-9.

10. Dlouhy M. Mental health services in the health accounts: the Czech Republic. Soc Psychiatry Psychiatr Epidemiol. 2011;46(6):447-53.

11. Czech Statistical Office. Výsledky zdravotnických účtů 2010 až 2015 [Results of Health Accounts 20102015]. Prague: Czech Statistical Office; 2016.

12. Institute of Health Information and Statistics. Psychiatrická péče 2015 [Psychiatric care 2015 ]. Prague: Institute of Health Information and Statistics; 2016.

13. Ministry of Health of the Czech Republic. Psychiatric care reform strategy. Prague: Ministry of Health of the Czech Republic; 2013.

14. Pec O. Mental health reforms in the Czech Republic. BJPsych Int. 2018:1-3.

15. Winkler P, Krupchanka D, Roberts T, Kondratova L, Machů V, Höschl C, et al. A blind spot on the global mental health map: a scoping review of 25 years' development of mental health care for people with severe mental illnesses in central and eastern Europe. Lancet Psychiatry. 2017;4(8):634 42.

16. Winkler P, Barrett B, McCrone P, Csémy L, Janoušková M, Höschl C. Deinstitutionalised patients, homelessness and imprisonment: systematic review. Br J Psychiatry. 2016;208(5):421-8.

17. Winkler P, Mladá K, Krupchanka D, Agius M, Ray MK, Höschl C. Long-term hospitalizations for schizophrenia in the Czech Republic 1998-2012. Schizophr Res. 2016;175(1):180-5.

18. Ministry of Health of the Czech Republic. Standard of care provided in mental health centres (MHC). Gazette of Ministry of Health. 2016;5:35-45.

19. OECD, Eurostat, World Health Organization. A system of health accounts: OECD publishing; 2011.

20. OECD. A system of health accounts, version 1.0. Paris: OECD; 2000.

21. World Health Organization. International statistical classification of diseases and related health problems. 10th revision, edition 2010. Malta: Wolrd Health Organization; 2011.

22. General Health Insurance Fund. An annual report of the general health Insurance Fund of the Czech Republic 2015. Prague: General Insurance Fund of the Czech Republic; 2016.

23. General Health Insurance Fund Ročenka 2015 [The Yearbook 2015]. Prague: General Health Insurance Fund; 2015.

24. Institute of Health Information and Statistics. Economic information on health care 2013. Prague: Institute of Health Information and Statistics; 2014.

25. Central bank exchange rates fixing [database on the Internet]2018. Available from: http://www.cnb. cz/en/financial_markets/foreign_exchange_market/exchange_rate_fixing/currency_average.jsp $\% 3 F c o d e \% 3$ DEUR. Accessed 24 Nov 2018.

26. Dlouhy M. Mental health care system and mental health expenditures in the Czech republic. J Mental Health Policy Econ. 2004;7(4):159-65.

27. Jacob K, Sharan P, Mirza I, Garrido-Cumbrera M, Seedat S, Mari JJ, et al. Mental health systems in countries: where are we now? Lancet. 2007;370(9592):1061-77.

28. Winkler P, Koeser L, Kondrátová L, Broulíková HM, Páv M, Kališová L, et al. Cost-effectiveness of care for people with psychosis in the community and psychiatric hospitals in the Czech Republic: an economic analysis. Lancet Psychiatry. 2018;5(12):1023-31.

29. Winkler P, Broulíková HM, Kondrátová L, Knapp M, Arteel P, Boyer P, et al. Value of schizophrenia treatment II: decision modelling for developing early detection and early intervention services in the Czech Republic. Eur Psychiatry. 2018;53:116-22.

Publisher's Note Springer Nature remains neutral with regard to jurisdictional claims in published maps and institutional affiliations. 
Hana M. Broulíková recently joined the Department of Health Sciences at Vrije Universiteit Amsterdam. She is further affiliated to Department of Public Mental Health at the National Institute of Mental Health.. Her main research interests are health care systems financing, and cost-effectiveness analysis of mental health care interventions. Based on her PhD project investigating cost-effectiveness of Alzheimer's disease early treatment, she has recently become a coordinator of the National Action Plan for Alzheimer's Disease and Related Illness currently developed by the Ministry of Health of the Czech Republic. Hana was awarded a Fulbright Scholarship to visit the Mailman School of Public Health, Columbia University in 2018.

Martin Dlouhý is a full associate professor at the Faculty of Informatics and Statistics, University of Economics in Prague. He is interested in health care financing, health services research and application of quantitative economic analysis in health care. He also lectures health policy and health economics at the Institute of Postgraduate Medical Education and First Faculty of Medicine, Charles University, Prague.

Petr Winkler is the head of the Department of Department of Public Mental Health at the National Institute of Mental Health, Czech Republic (NIMH CZ). After graduating in Social Policy and Social Work at the Charles University in Prague, he became one of the Bakala Foundation scholars and went to the Institute of Psychiatry, Psychology and Neuroscience, King's College London, to pursue his $\mathrm{PhD}$ in mental health economics. Petr's main expertise is in mental health care systems, psychiatric epidemiology, and health economics, and he is also interested in suicidology, stigma and discrimination, and socio-cultural aspects of psychedelic movement in psychiatry. In the past few years he has been involved in the development and implementation of the mental health care reform strategy in the Czech Republic; currently he is leading nation-wide projects on destigmatization, early interventions in psychosis, and system for evidence based mental health care development. Petr was awarded European Psychiatric Association research prize for the best paper published in 2016 in the category Psychiatric epidemiology, social psychiatry and psychotherapeutic interventions in mental disorders. $\mathrm{He}$ is also engaged in mental health care research and development in the region of post-communist Central and Eastern Europe. 